\title{
A Tri-Band-Pass Microstrip Filter for Microwave Applications
}

\author{
Suhas S. Gayke \\ P. G. Dept., MBES College of Engineering, \\ Ambajogai, India, 4315172
}

\author{
Veeresh G. Kasabegoudar \\ P. G. Dept., MBES College of Engineering, \\ Ambajogai, India, 4315172
}

\begin{abstract}
In this paper, a tri-band-pass filter suitable for microwave applications is presented. The proposed band pass filter consists of four rectangular patches (cells) separated by four rectangular slots. The selectivity of the pass bands is adjusted by adjusting the position of transmission zeros (TZs). The locations of the TZs can be adjusted for different selectivity of the filter, by adjusting the dimensions of the rectangular cells. Also, the band pass filter's centre frequency and bandwidth of the tri pass bands are independently adjusted by changing the length and width between pass band edges, which makes the design very simple. Measured results merely agree with the simulated values.
\end{abstract}

\section{Keywords}

Asymmetric CCMRC, band pass filter, transmission zeros.

\section{INTRODUCTION}

Band pass filter is a piece of electrical circuit to pass a desired frequency band and rejects other unwanted frequencies outside the desired band. The rapid growth of microwave communication system technology, planar filters find most suitable for these applications. Microstrip band pass filters are the good candidates to meet these demands as these are small in size, low cost, easy to fabricate, high performance and multi-frequency.

The main issue of any filter component is its size and can be solved by ACCMRC (Asymmetric Complementary Compact Micro Strip Resonant Cell) filter [1] which has a triangular patch with transmission zeros to achieve dual band pass characteristics. ACCMRC has made up of combination of two half-CCMRCs. Two different half-CCMRCs are combined into an asymmetric CCMRC (ACCMRC), which has dualband response. Due to its compactness structure and dual band response size problem is solved [1]. However, this geometry offers only dual bands.

On the other hand selectivity issue is addressed by increasing the order of these filters. However, the size, cost and complexity of filter increases $[2,3]$. The best way to solve the frequency selectivity problem is to produce a transmission zeros near the pass band edge [1]. In [4], to analyze microstrip line filter, coupled resonator theory is used, and it is shown that cross-couplings between non-adjacent resonators can generate TZs, resulting in elliptic or quasi-elliptic function frequency response[5 -10]. Slots are added on rectangular patch such that four cells are created out of which top two and bottom two cells are symmetrical in dimensions. This results in the tri pass band response [11-15]. Also, by adjusting the position of transmission zeros filter is operated for different selectivity $[16,17]$. In this work to excite the tri pass band response, rectangular patch is used instead of triangular patch as suggested in [1] Also, the presented filter here is simple in structure, compact size, and produces tri pass bands.

More details on the proposed geometry are discussed in subsequent sections. Section 2 presents the geometry structure of the proposed filter. Design and optimization procedure of the proposed filter is presented in Section 3. Section 4 presents the validation of the fabricated prototype, and discussions on the measured results are also presented there. Finally, conclusions of this study are presented in Section 5.

\section{FILTER GEOMETRY}

Figure 1(a) shows the basic geometry of proposed tri band pass filter using rectangular patch for microwave applications. As stated earlier, four unequal cells are etched making use of slots on rectangular patch. The detailed optimization procedure of the proposed filter and its optimum dimensions, and characteristics are presented in Section 3. All parameters of the optimized geometry are shown in Figure 1 and its optimized values are indicated Table 1. The filter was optimized to obtain tri pass bands which are centered at 6.60 $\mathrm{GHz}, 7.10 \mathrm{GHz}$, and $8.19 \mathrm{GHz}$. Also, these are indicative frequencies and can be tuned by slot dimensions. Next section gives the detailed optimization procedure of the proposed filter.

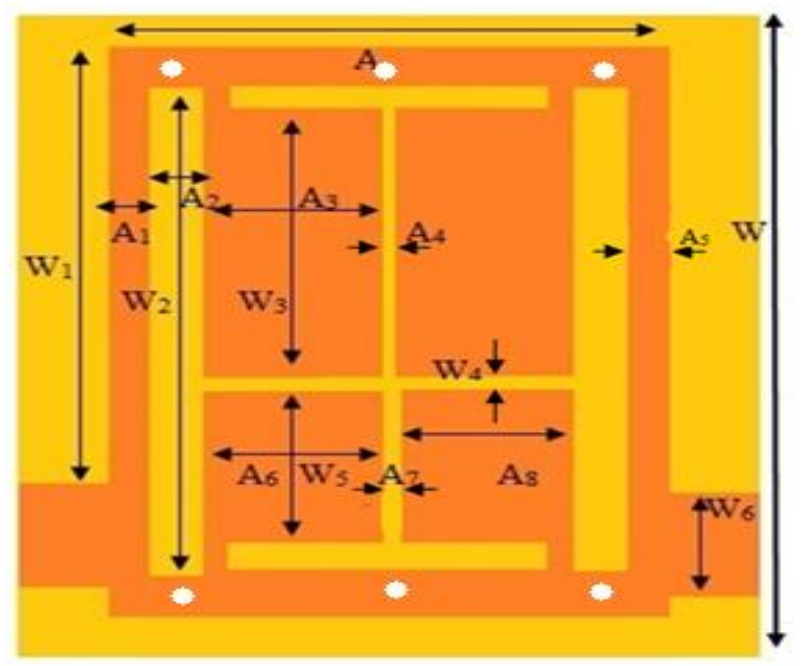

Figure.1: Geometry layout of the proposed filter

Table 1: Dimension parameters of optimized filter geometry.

\begin{tabular}{|c|c|}
\hline \multicolumn{2}{|c|}{ geometry. } \\
\hline $\mathrm{A}$ & Dimensions $(\mathbf{m m})$ \\
\hline $\mathrm{A}_{1}$ & 9.6 \\
\hline $\mathrm{A}_{2}$ & 1.45 \\
\hline
\end{tabular}




\begin{tabular}{|c|c|}
\hline $\mathrm{A}_{3}$ & $\mathbf{1 . 6}$ \\
\hline $\mathrm{A}_{4}$ & $\mathbf{0 . 2}$ \\
\hline $\mathrm{A}_{5}$ & $\mathbf{2 . 4 5}$ \\
\hline $\mathrm{A}_{6}$ & $\mathbf{1 . 6}$ \\
\hline $\mathrm{A}_{7}$ & $\mathbf{0 . 2 5}$ \\
\hline $\mathrm{A}_{8}$ & $\mathbf{1 . 5 5}$ \\
\hline $\mathrm{W}$ & $\mathbf{1 0 . 8}$ \\
\hline $\mathrm{W}_{1}$ & $\mathbf{8 . 6}$ \\
\hline $\mathrm{W}_{2}$ & $\mathbf{8 . 4 5}$ \\
\hline $\mathrm{W}_{3}$ & $\mathbf{1 . 2}$ \\
\hline $\mathrm{W}_{4}$ & $\mathbf{0 . 4}$ \\
\hline $\mathrm{W}_{5}$ & $\mathbf{2}$ \\
\hline $\mathrm{W}_{6}$ & $\mathbf{2}$ \\
\hline
\end{tabular}

\section{GEOMETRY OPTIMIZATION AND}

\section{DISCUSSIONS}

In this section parametric study is conducted to optimize the proposed filter. The key design parameters used for the optimization are length and width between rectangular patch, fiddling position and radius of transmission zeros. The detailed analysis of these parameters is investigated in the following paragraphs of this section.

\subsection{Effect of Width $\left(A_{2} \& A_{4}\right)$}

In this study we started the optimization with parameter $\mathrm{A}_{2}$. This parameter was changed from $1.1 \mathrm{~mm}$ to $1.2 \mathrm{~mm}$ in steps $0.05 \mathrm{~mm}$. Reflection and transmission coefficient characteristics are plotted in Figure 2 (a). From the response it may be noted that $\mathrm{A}_{2}=1.15 \mathrm{~mm}$ offers the flat response compared to other cases. Similarly, in another study, $\mathrm{A}_{4}$ was changed from $0.15 \mathrm{~mm}$ to $0.25 \mathrm{~mm}$ in steps of $0.05 \mathrm{~mm}$. In this case optimum response was obtained for $0.2 \mathrm{~mm}$ (Figure 2(b)).

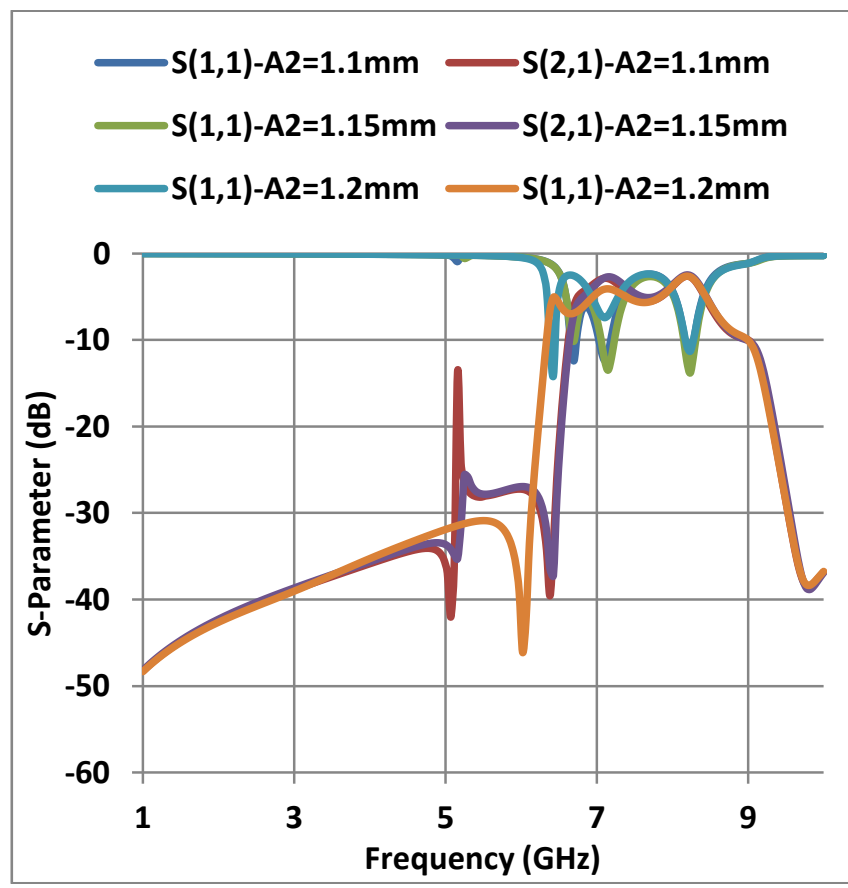

(a)

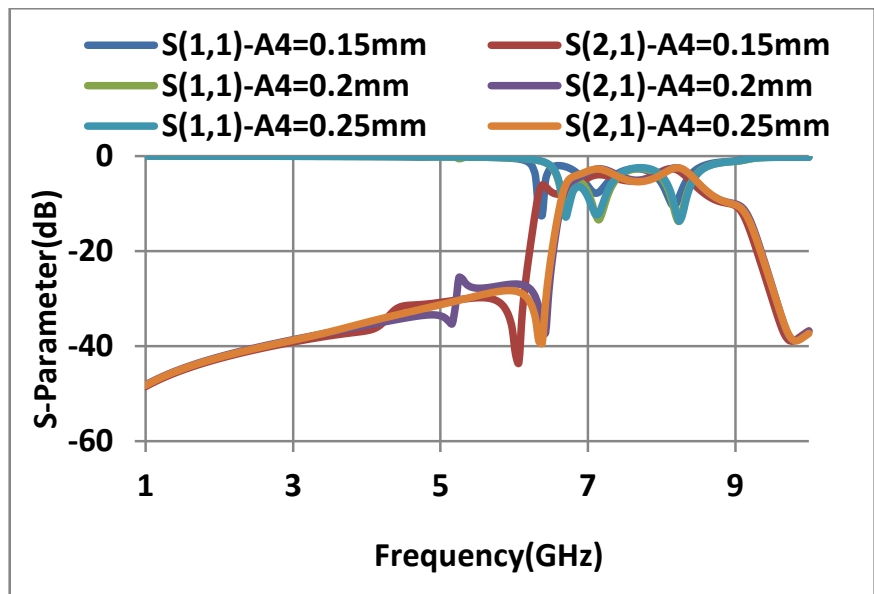

(b)

Figure 2: Simulated $S_{11}$ and $S_{21}$ vs. $A_{2}$ and $A_{4}$ (a) $A_{2}$ (b)

$\mathbf{A}_{4}$.

3.2 Effect of Length $\left(W_{2} \& W_{4}\right)$

In another effort we studied the effect of $\mathrm{W}_{2}$ and $\mathrm{W}_{4}$ on the filter response. In the first case $\mathrm{W}_{2}$ was changed from $8.35 \mathrm{~mm}$ to $8.55 \mathrm{~mm}$. Incremental size of $0.1 \mathrm{~mm}$ was used. All these responses are presented in Figure 3(a). Similarly, $\mathrm{W}_{4}$ was changed from $0.15 \mathrm{~mm}$ to $0.25 \mathrm{~mm}$ with step size of $0.05 \mathrm{~mm}$ (Figure 3(b)). From these two studies we found that $\mathrm{W}_{2}=8.45 \mathrm{~mm}$ and $\mathrm{W}_{4}=0.2 \mathrm{~mm}$ as the optimum values.

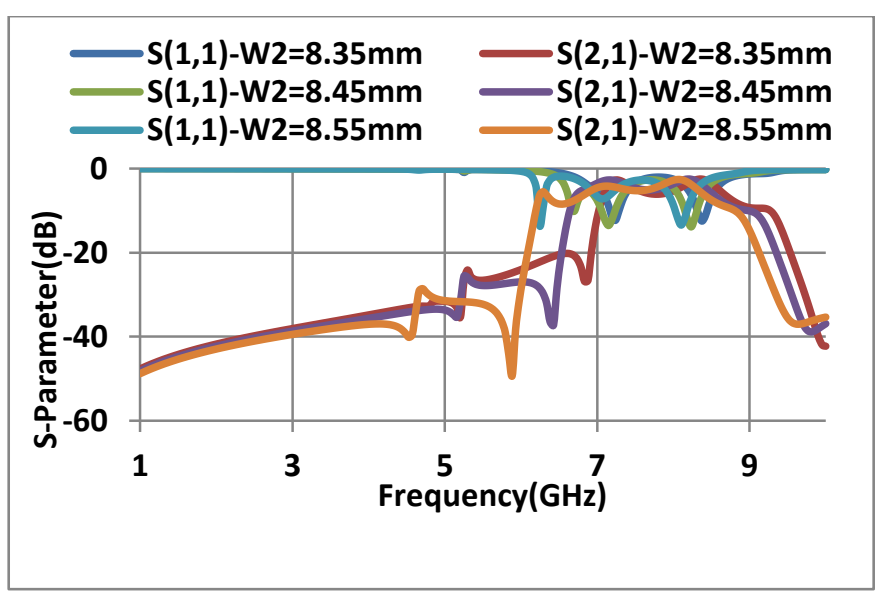

(a)

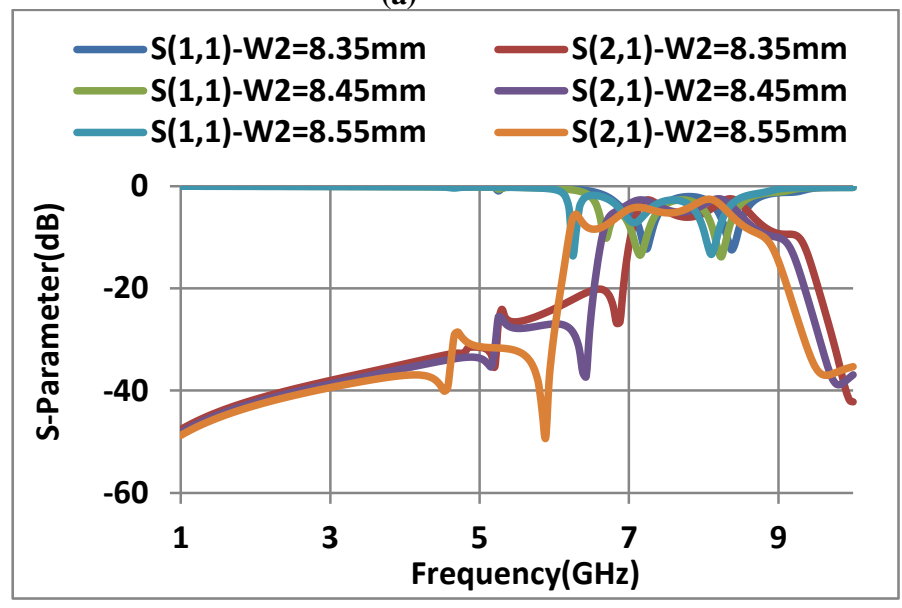

(a) 


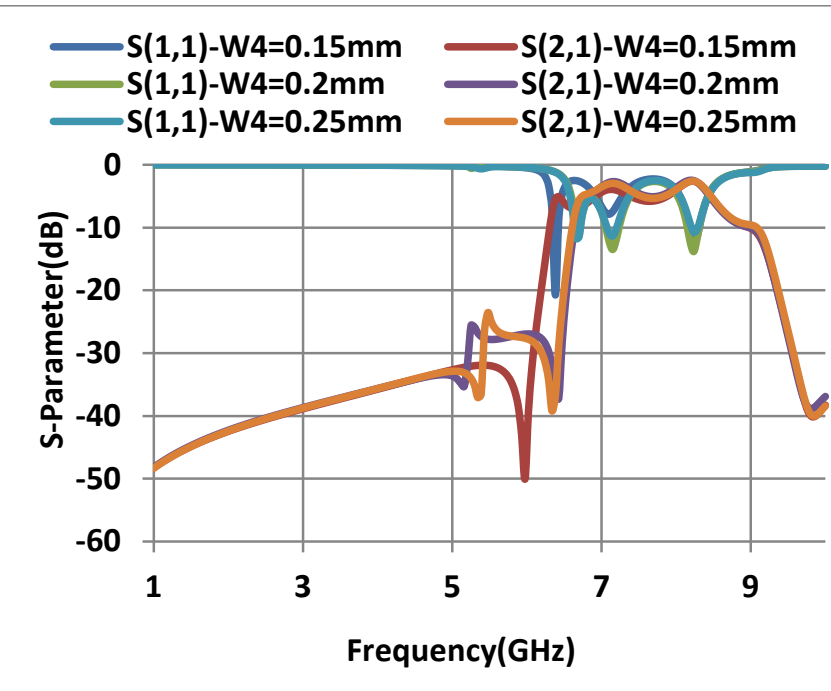

(b)

Figure 3: Simulated $S_{11}$ and $S_{21}$ vs. $W_{2}$ and $W_{4}\left(\right.$ a) $W_{2}$ (b) $\mathrm{W}_{4}$

\subsection{Effect of Feeding Position (W1)}

In this we investigated the effect of feeding position $\mathrm{W}_{1}$. Here, the feed position $\mathrm{W}_{1}$ was varied from $8.55 \mathrm{~mm}$ to $8.65 \mathrm{~mm}$ in steps of $0.05 \mathrm{~mm}$. S-parameters of this study are indicated in Figure 4. From the Figure 4, it may be noticed that $\mathrm{W} 1=8.6 \mathrm{~mm}$ is the optimum value of feed position as it offers good results.

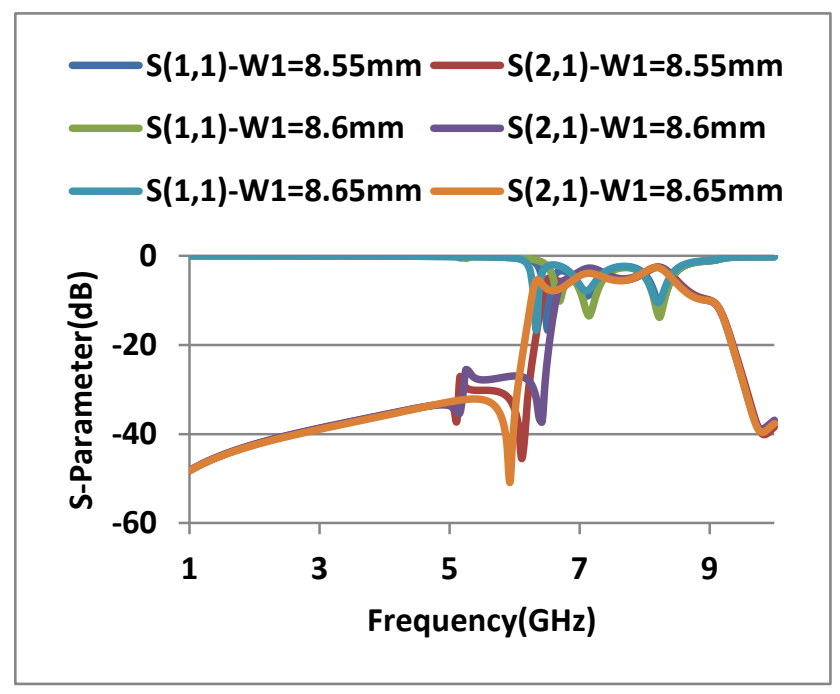

Figure 4: Simulated $S_{11}$ and $S_{21}$ vs. W1

\subsection{Effect of Radius of Vias}

In yet another effort, the radius of vias was varied to observe the effect on filter response. The radius was varied $0.2 \mathrm{~mm}$ to $0.4 \mathrm{~mm}$ in steps of $0.1 \mathrm{~mm}$. As the radius of the via changes, the resonant frequency of all the bands get shifted. From the study $\mathrm{R}=0.3 \mathrm{~mm}$ was noted as the optimum value.

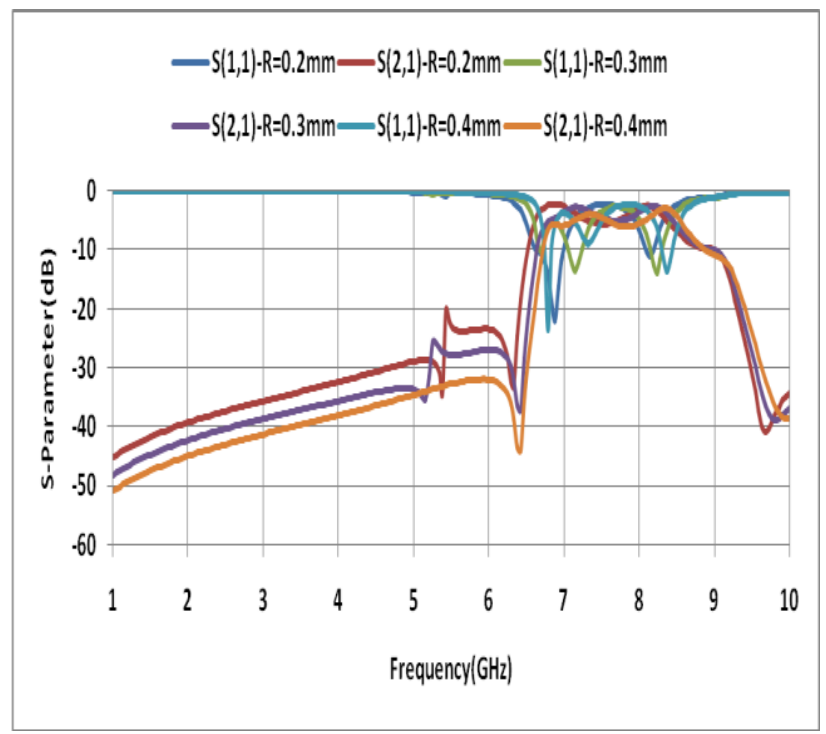

Figure 5: Simulated $S_{11}$ and $S_{21}$ vs. $R$

From the detailed parametric study conducted we obtained an optimum set of dimension which is listed in Table 1.

\section{EXPERIMENTAL VALIDATION OF THE GEOMETRY AND DISCUSSIONS}

The proposed geometry shown in Figure 1 with its optimized dimensions listed in Table 1 is fabricated on FR4 substrate having dielectric constant of 4.4 and thickness of $1.27 \mathrm{~mm}$ Radius of vias is $\mathrm{R}=0.3 \mathrm{~mm}$. The photograph of fabricated prototype is shown in Figure 6. In Figure 7, the setup of measurement of reflection coefficient of the filter in real time environment is shown. Reflection and transmission coefficient characteristics of measured results are compared with simulated values in Figure 8. The measured results slightly mismatch with the simulated values which may be due to inaccuracies in the fabricated prototype.

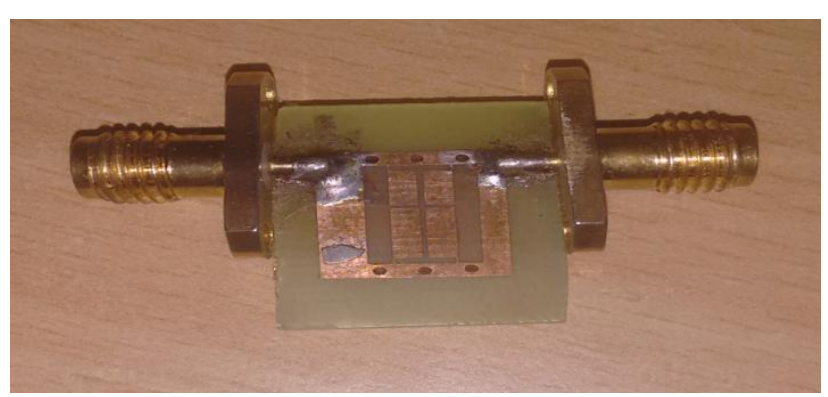

Figure 6: Photograph of fabricated prototype

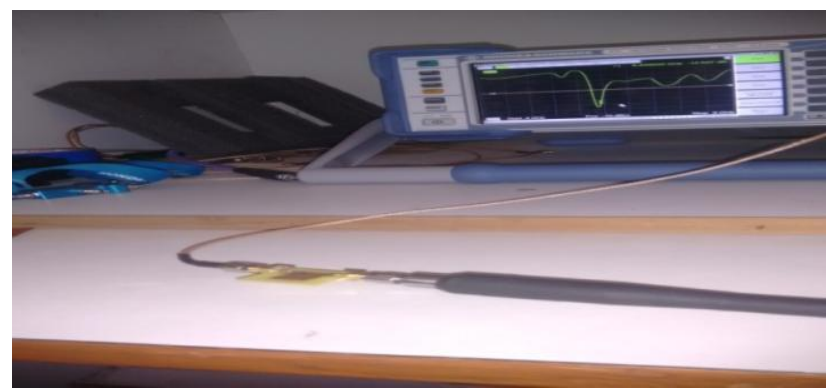

Figure 7: Photograph of measurement setup. 


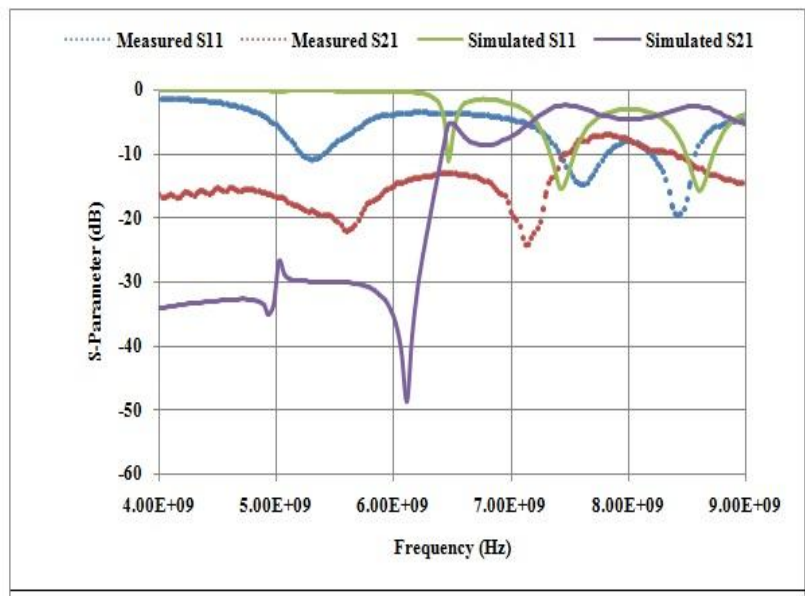

Figure 8: Comparison of simulated and measured $S_{11}$ and $S_{21}$

\section{CONCLUSIONS}

A tri band pass filter with its characteristics, and design methods are investigated thoroughly. From the studies it can be revealed that the filter's selectivity can be adjusted by changing the length and width of rectangular cell. The tri band pass filter is realized by adding asymmetrical (along horizontal) slots on rectangular patch. The proposed band pass (BPF) filter is very flexible as its bands can be tuned independently. Thus, the tri pass band filter can be a good candidate for microwave BPF designs. Future scope includes enhancement of pass band characteristics and possible excitation of four bands.

\section{REFERENCES}

[1] W. Qin, and Q. Xue, "Complementary compact microstrip resonant cell and its applications to microwave single- and dual-band bandpass filters," IEEE Transactions on Microwave Theory and Techniques, vol. 61, no. 2, pp.773-781, February 2013.

[2] J. S. Hong and M. J. Lancaster, Microstrip Filters for RF/Microwave Applications, New York: Wiley, 2001.

[3] J. S. Hong and M. J. Lancaster, "Couplings of micro strip square open loop resonators for cross-coupled planar microwave filters," IEEE Trans. Microw. Theory Tech., vol. 44, no. 11, pp. 2099-2109, Nov. 1996.

[4] Z. B. Wang, S. J.Gao, F.Nasri, and C. W. Park, "High power added efficiency power amplifier with harmonic controlled by UWB filter with notched band at 6.42 $\mathrm{GHz}$," in Proc. IEEE $12^{\text {th }}$ Annual Wireless and Microwave Technology Conf. (WAMICON)

[5] Y. T. Lee, J. Lee, and S. Nam, "A new phase noise reduction method of oscillator by loaded Q improvement using dual feedback topology," IEEE Microw. Wireless Compon. Lett., vol. 15, no. 1, pp. 39-41, Jan. 2005.
[6] L. H. Hsieh and K. Chang, "Tunable microstrip bandpass filters with two transmission zeros," IEEE Trans. Microw. Theory Tech., vol. 51, no. 2, pp. 520-525, Feb. 2003.

[7] G. L. Dai, X. Y. Zhang, C. H. Chan, Q. Xue, and M. Y. $\mathrm{Xia}$, "An investigation of open- and short-ended resonators and their applications to bandpass filters," IEEE Trans. Microw. Theory Tech., vol. 57, no. 9 pp. 2203-2210, Sep. 2009.

[8] S. C. Lin, C. H. Wang, Y. S. Lin, and C. H. Chen, "Dual quarter wavelength hairpin bandpass filter with multiple transmission zeros," in Proc. 2006 IEEE MTT-S Int. Microwave Symp Dig., pp. 361-364. 2006.

[9] Y. C. Li, X. Y. Zhang, and Q. Xue, "Bandpass filter using discriminating coupling for extended out-of-band suppression," IEEE Microw. Wireless Compon. Lett., vol. 20, no. 7, pp. 369-371, Jul. 2010.

[10] Q. Xue, K. M. Shum, and C. H. Chan, "Novel 1-D microstrip PBG cells," IEEE Microw. Guided Wave Lett., vol. 10, no. 10, pp. 403-405, Oct. 2000.

[11] L. H. Hsieh and K. Chang, "Tunable microstrip bandpass filters with two transmission zeros," IEEE Trans. Microw. Theory Tech., vol. 51,no. 2, pp. 520-525, Feb. 2003.

[12] G. L. Dai, X. Y. Zhang, C. H. Chan, Q. Xue, and M. Y. $\mathrm{Xia}$, "An investigation of open- and short-ended resonators and their applications to bandpass filters," IEEE Trans. Microw. Theory Tech., vol. 57, no. 9,pp. 2203-2210, Sep. 2009.

[13] S. C. Lin, C. H. Wang, Y. S. Lin, and C. H. Chen, "Dual quarter wavelength hairpin bandpass filter with multiple transmission zeros,"in Proc. 2006 IEEE MTT-S Int. Microwave Symp. Dig., pp. 361-364.2006

[14] Y. C. Li, X. Y. Zhang, and Q. Xue, "Bandpass filter using discriminating coupling for extended out-of-band suppression," IEEE Microw. Wireless Compon. Lett., vol. 20, no. 7, pp. 369-371, Jul. 2010.

[15] Q. Xue, K. M. Shum, and C. H. Chan, "Novel 1-D microstrip PBGcells," IEEE Microw. Guided Wave Lett., vol. 10, no. 10, pp. 403-405, Oct. 2000.

[16] J. S. Hong and M. J. Lancaster, "Couplings of microstrip square open loop resonators for cross-coupled planar microwave filters," IEEE Trans. Microw. Theory Tech. vol. 44, no. 11, pp. 2099-2109, Nov.1996.

[17] J. S. Hong and M. J. Lancaster, "Cross-coupled microstrip hairpin-resonator filters," IEEE Trans. Microw. Theory Tech., vol. 46, no. 1, pp.118-122, Jan. 1998. 